\title{
A cooperação técnica Opas-Brasil e o desenvolvimento de recursos humanos em saúde: trajetórias históricas e agendas contemporâneas DOI: 10.3395/reciis.v4i1.347pt
}

\section{Fernando A. Pires-Alves}

Historiador, Fundação Oswaldo Cruz,

Rio de Janeiro, Brasil

fapires@fiocruz.br

\section{Carlos Henrique Assunção Paiva}

Historiador, Fundação Oswaldo Cruz,

Rio de Janeiro, Brasil

chapaiva@gmail.com

\section{José Paranaguá de Santana}

Médico, Representação da OPAS no Brasil, Brasilia, DF, Brasil

\section{Diego Victoria Mejía}

Engenheiro, Representante da OPAS no Brasil, Brasilia, DF, Brasil

\begin{abstract}
Resumo
Esse trabalho discute, em perspectiva histórica, a cooperação técnica estabelecida entre a Organização Pan-Americana da Saúde (Opas/OMS) e o governo brasileiro no domínio das políticas e programas de desenvolvimento de recursos humanos em saúde, a partir de meados da década de 1970. Considerando os organismos intergovernamentais, simultaneamente, como atores relevantes e arenas de negociação, as iniciativas deflagradas no âmbito da cooperação técnica são analisadas como contribuição fundamental para a institucionalização da área de recursos humanos em saúde no país, como parte das instâncias de gestão pública da saúde e como um acervo original de arranjos institucionais, experiências e abordagens metodológicas. Sempre recorrendo a documentos oficiais e a depoimentos de história oral, a cooperação Opas-Brasil é também discutida como espaço institucional singular, com atuação relevante para a organização do campo da saúde coletiva no Brasil e a própria gestação política do Sistema Único de Saúde brasileiro. Por fim, as ações da cooperação são analisadas como matrizes das experiências de cooperação técnica que se implementaram sob o arcabouço institucional do novo sistema de saúde brasileiro, cujos desdobramentos podem ser identificados na agenda e modo de operação da cooperação técnica tal como realizada nos dias de hoje.
\end{abstract}

\section{Palavras-chave}

história da saúde; recursos humanos em saúde; cooperação técnica em saúde; saúde internacional
A Organização Pan-americana da Saúde (Opas/OMS), desde sua criação como Oficina Sanitária Internacional, em 1902, esteve frequentemente envolvida na realização de iniciativas no âmbito das quais se pretendeu influir na quantidade, qualidade, perfil e modo de atuação do profissional médico e do trabalhador em saúde nas Américas (CUETO, 2007). As relações entre a Opas e o Brasil não fugiram a este padrão.

Ao longo das décadas de 1960 e 1970, todavia, estas ações ganharam uma nova dimensão e um novo significado. Na esteira do final da II Guerra e da emergência do desenvolvimento como idéia orientadora das políticas públicas e do planejamento como umas das suas formas de realização, os trabalhadores e a sua capacidade de trabalho passaram a ser considerados como um dos recursos-chave a serem mobilizados na empreitada desenvolvimentista. É o momento do surgimento da Economia da Educação e, como parte do seu acervo teórico, das teorias do capital humano (ESCOBAR, 1998; RIST, 2002). No caso da Opas, é sintomática desta tendência, a criação, na metade da década de 1960, de uma área operacional especialmente voltada ao desenvolvimento de recursos humanos. A partir de então, as sua ações neste domínio se pretenderam mais articuladas e integradas aos planos regionais e nacionais de saúde (FERREIRA, 2005).

Por outro lado, o desenvolvimento e as práticas de assistência para o desenvolvimento foram concebidos 
e realizados sob a moldura da Guerra Fria. A Aliança para o Progresso, lançada em 1961, pode ser tomada, para o contexto americano, como exemplo de iniciativa concebida sob a lógica da contenção de uma possível expansão do socialismo nas Américas (TAFFET, 2007). Por outro lado, muito cedo na história do pós-guerra, as relações entre nações industrializadas, agências intergovernamentais e países em desenvolvimento, foram também emolduradas pelo conflito norte-sul, em suas várias manifestações. O final da década de 1960 e os anos subsequentes testemunharão, por exemplo, a emergência da noção de cooperação técnica entre países em desenvolvimento, que revelava a tentativa de estabelecer práticas de cooperação baseadas nas idéias de soberania e autonomia, de interação entre iguais, de apropriação efetiva dos conhecimentos e tecnologias envolvidos nos processos de cooperação. Estas últimas noções implicavam reconhecer já àquela época, que alguns dos países em desenvolvimento dispunham de competências suficientes, pelo menos em algumas áreas específicas. Indicava que a cooperação podia ser também um processo de construção coletiva de conhecimentos e práticas inovadoras (FERREIRA, 1976).

Mais tarde, temas como o desenvolvimento sustentado, a integração regional, e a cooperação sul-sul, atualizariam estas agendas. As iniciativas conjuntas da Opas e os seus Estados Membros, como não poderia ser diferente, foram informadas, a cada tempo e circunstância, pela sua inscrição nesta trajetória histórica.

Este trabalho analisa o processo de gênese e desenvolvimento de um acordo de cooperação técnica em recursos humanos para a saúde, celebrado entre a Opas e o governo brasileiro em meados da década de 1970, cujos desdobramentos se fazem presentes ainda nos dias de hoje. Pela primeira vez, neste contexto nacional, as ações de colaboração orientadas para os recursos humanos em saúde se apresentariam enfeixadas sob a forma de um programa articulado. As grandes linhas de atuação desta cooperação, assim como os seus principais resultados, serão indicados e descritos sumariamente. Destacaremos, todavia, quais as estratégias e as formas de organização então adotadas e de que maneira estas foram moldadas segundo as possibilidades proporcionadas pelo contexto histórico institucional brasileiro no período. Numa terceira seção é apresentado, em linhas gerais, um percurso histórico das agendas diplomáticas brasileiras, que culmina em uma inédita centralidade para temas como direitos humanos, ambiente e saúde. Finalmente, discute-se de que modo a colaboração entre a Opas e o governo brasileiro é hoje percebida como uma possível matriz para novas experiências no contexto da cooperação Sul-Sul.
Nossa abordagem pressupõe que organismos intergovernamentais como a Opas são tanto atores sociais relevantes, quanto arenas de negociação. Como atores são capazes de produzir realidades, pela ação direta no terreno prático, pela produção e disseminação de valores, normas e modelos de atuação, pela definição de molduras cognitivas (FINNEMORE, 1996). São também arenas de negociação, na medida em que são permeáveis à expressão de interesses de origens diversas, seja de natureza estatal, infra-estatal ou extraestatal. São arenas, ainda, porque também os interesses de suas burocracias internas manifestam-se em situações de concorrência. Vale dizer, ainda, que seus escritórios de campo, suas representações nos países são especialmente sensíveis ao jogo de forças presentes nos ambientes institucionais com os quais se relacionam diretamente (PIRES-ALVES \& PAIVA, 2006).

\section{O acordo de cooperação, suas linhas de atuação e desenvolvimento}

Em finais de 1973 foram dados os primeiros passos para a implementação de uma cooperação técnica entre a Opas e o governo brasileiro em recursos humanos para a saúde, sob a forma de um programa articulado de ação. Em novembro daquele ano, os ministérios da Saúde, da Educação e Cultura, e a organização assinaram o Acordo para um Programa Geral de Desenvolvimento de Recursos Humanos em Saúde. Seus desdobramentos culminaram na proposição, em 1976, daquele que seria o seu programa de ação fundador: o Programa de Preparação Estratégica de Pessoal de Saúde, o PPREPS (OPAS-BRASIL, 1973, 1975a).

O PPREPS teria como meta formal ajustar a formação de recursos humanos para a saúde no país às necessidades do recém criado Sistema Nacional de Saúde e em acordo com as diretrizes do II Plano Nacional de Desenvolvimento, ambos de 1975. Pretendia-se, no terreno dos recursos humanos, dar sustentação a uma ampliação da cobertura da atenção à saúde regionalizada, segundo os diferentes níveis de complexidade e ajustada à realidade socioeconômica das várias regiões do país.

Tendo em vista este objetivo mais geral, definiram-se três objetivos específicos. No primeiro deles, pretendia-se formar, em grande escala, pessoal de saúde de nível técnico e auxiliar. Estimou-se, à época, um contingente entre 160 e 180 mil pessoas formadas durante o período compreendido entre de 1976-1979, contemplando um variado leque de categorias profissionais, com ênfase naquelas profissões diretamente ligadas à prestação de serviços assistenciais. Entre estas se 
incluem técnicos e auxiliares de enfermagem, atendentes e agentes comunitários. No segundo objetivo, o PPREPS apoiaria a criação de dez regiões docente-assistenciais de saúde. Buscava-se, em cada região, integrar o ensino superior das profissões de saúde e a atenção à saúde nos seus vários níveis, como forma de promover a transformação das práticas de ensino e da própria organização dos serviços; de promover a regionalização dos serviços e de contribuir para a definição de um novo rumo na formação de pessoal de saúde. Com o terceiro objetivo a Cooperação Opas-Brasil deveria oferecer suporte à criação de um sistema de desenvolvimento de recursos humanos para a saúde nos diversos estados federativos, estimulando, ainda, uma possível articulação com os sistemas de planejamento setorial estaduais e nacionais (PPREPS, 1976; 1979).

Ao longo dos primeiros trinta anos de existência do Acordo de Cooperação, mediante sucessivas renovações, o ritmo de trabalho e os resultados alcançados em cada uma das suas frentes de atuação foram desiguais (PIRES-ALVES \& PAIVA, 2006; CASTRO, 2008). Detalhar suas realizações, seus êxitos e vicissitudes, está muito além do escopo deste trabalho. Porém, uma síntese destes desenvolvimentos será necessária para conferir sentido às discussões que se seguirão.

A ações voltadas para implementação das regiões docentes-assistenciais, a princípio, restringiram-se ao apoio a algumas poucas iniciativas de caráter experimental. Superar resistências, sobretudo no âmbito das instituições do ensino superior médico, revelou-se um desafio de difícil superação (PPREPS, 1979). Após a redemocratização do país, esta agenda foi retomada e vários projetos IDA foram implementados ou ampliados, com base em iniciativas anteriores que contaram com apoio externo, a exemplo da Fundação Kellogg. Componentes programáticos importantes foram alterados ao longo do tempo. Entre estes, podese mencionar, por exemplo, a tentativa de empreender projetos multi-departamentais e de incluir as comunidades na construção e condução dos projetos (ROCHA, 1985). As dificuldades institucionais, entretanto, persistiram e esta é uma agenda ainda atual, do que é testemunho o lançamento pelo governo brasileiro, em 2005, do Pró-Saúde, um programa de reorientação do ensino profissional de saúde, assentado na integração docente-assistencial e foco na atenção básica e que também contou com a participação da Opas-Brasil (SESU-MEC, 1981; SANTANA, 2006). A este respeito, os primeiros anos da Cooperação Opas-Brasil representaram um aprendizado, ao contribuir para o desenvolvimento de uma base conceitual e metodológica comum, assim como para a criação de uma rede de projetos e instituições cuja existência constituíram base de apoio relevante para as ações futuras.

Na formação de pessoal auxiliar e técnico em saúde, os resultados foram mais auspiciosos desde os primeiros anos do Acordo de Cooperação. Após três anos de programa, já haviam sido capacitados trinta e nove mil pessoas, em 14 estados da federação (PPREPS, 1978). Em 1981, teve início uma nova fase, que foi informalmente batizada como o Projeto Larga Escala, com a expectativa de capacitar duzentas mil pessoas. Uma reversão nas expectativas do regime militar em seus últimos anos de vigência, todavia, limitou as metas quantitativas e suscitou a ênfase nos aspectos metodológicos e em uma opção político-pedagógica pela idéia de formação do pessoal de saúde em oposição a idéia de treinamento (PDRHS, 1985). Desta forma, o projeto afastou-se decisivamente das iniciativas de instrução de trabalhadores baseadas em uma estrita racionalidade econômica.

Por esta via, a experiência em torno do Larga Escala legou uma metodologia de ensino que procurou enfrentar a desafiante questão de realizar a formação profissional técnica, sem afastar o trabalhador das suas atividades. Pretendeu-se, ao mesmo tempo, possibilitar a este aluno-trabalhador o acesso à educação geral, percorrer um currículo formal e obter uma titulação. Entre seus principais pressupostos figuravam a indissociabilidade entre o método e o conteúdo, assim como a possibilidade de apropriação da estrutura do conhecimento pelo aprendiz (SANTOS, 2002; CASTRO, 2008).

A implementação do projeto e seus desdobramentos suscitaram a instituição de centros formadores de pessoal de saúde nos estados; de núcleos de desenvolvimento de recursos humanos junto às secretarias de saúde e, mais tarde, a constituição de uma rede de escolas técnicas multiprofissionais orientadas para o setor saúde. Em 2002, existia uma rede de 25 escolas e centros formadores, presentes em 15 estados brasileiros. Seus fundamentos remontam, sem dúvida, às ações da Cooperação Opas-Brasil (PIRES-ALVES \& PAIVA, 2006; CASTRO, 2008).

Operando de forma descentralizada desde seu início, a cooperação técnica favoreceu a instituição de estruturas e grupos profissionais regionais dedicados à formação de recursos humanos em saúde, nos seus mais variados níveis, parte delas já mencionadas no parágrafo anterior. Entre outras ações importantes desta ordem deve-se incluir o apoio à criação e desenvolvimento de Núcleos de Estudos de Saúde Pública e de Núcleos de Saúde Coletiva nas universidades, núcleos estes que tiveram um papel destacado na consolidação da reforma sanitária brasileira. Outra iniciativa foi a instituição, em 1987, com a participação direta destes núcleos, do Curso de Aperfeiçoamento em 
Desenvolvimento de Recursos Humanos em Saúde, o CADRHU. Entre 1987 e 1990, 974 alunos concluíram as trinta e sete edições do curso, realizados no estados, por mais de uma centena de docentes previamente capacitados. Os cursos são ministrados até os dias de hoje, ainda que o seu ritmo de realização tenha oscilado sensivelmente ao longo do tempo (CADRHU, 1991).

Com características assemelhadas, foi o Projeto de Desenvolvimento Gerencial de Unidades de Saúde-Gerus, realizado a partir de 1992. Seu propósito foi realizar o treinamento de gestores em unidades ambulatoriais, no momento em que a municipalização dos serviços gerava novos desafios aos gestores dessa esfera de governo. Mais uma vez, o projeto foi concebido segundo o que era percebido como necessidades advindas da implantação do SUS; adotou uma concepção pedagógica alicerçada na idéia de uma solidariedade transformadora, compartilhada pelos envolvidos no processo ensino-apredizagem; e a sua implementação envolveu uma ativa mobilização de instâncias e atores regionais e locais (CASTRO, 2008).

Iniciativas como as descritas acima desempenharam papel importante, senão decisivo na própria constituição do campo dos recursos humanos em saúde, como área de conhecimento, domínio de práticas e rede de atores sociais concretos. Em 1999, boa parte destes recursos institucionais foi mobilizada pelo Ministério da Saúde do Brasil para instituir a Rede Observatório de Recursos Humanos em Saúde, em resposta a uma estratégia regional instituída pela Opas, em associação com o Banco Mundial, a Organização Internacional do Trabalho e a USAID. Para avançarmos sobre como estes resultados que se tornaram possíveis no contexto histórico que estamos considerando será preciso examinar as forma de organização da Cooperação Opas-Brasil, as estratégias que adotou e as suas implicações.

\section{Arranjos e estratégias institucionais}

Uma iniciativa de colaboração entre países, sobretudo pensada em termos de assistência técnica, é normalmente concebida como o fruto da necessidade e do desejo de um país que será recebedor da assistência, por um lado, e, de outro, da disponibilidade e do interesse - e eventualmente de uma capacidade de indução - de um país ou de uma agência intergovernamental, considerados os ofertantes dos recursos e meios necessários. A análise histórica acerca dos arranjos institucionais, dos recursos financeiros e das reservas de conhecimento e experiência mobilizadas no desenrolar da cooperação Opas-Brasil em recursos humanos, revelam o quanto estas arquiteturas institucionais podem ser complexas e, eventualmente, surpreendentes.

Em primeiro lugar os recursos financeiros despendidos na empreitada foram todos de origem nacional. Em meados dos anos 1970, o governo autoritário brasileiro via-se às voltas com o desafio de sustentar altas taxas de crescimento econômico em um cenário internacional afetado negativamente pela primeira crise do petróleo. O regime tentava também reverter um quadro de desagregação de suas bases político-sociais, mediante a adoção de políticas sociais compensatórias. Para tanto, foi preciso sustentar o volume de gastos públicos e investimentos recorrendo a fontes de endividamento externo. Foi preciso, ainda, mobilizar capacidades profissionais e gerenciais, eventualmente apenas disponíveis em instituições e comunidades profissionais ideologicamente mais alinhadas a um rejuvenescido movimento oposicionista. Isto significou mobilizar novos quadros e disponibilizar recursos para grupos profissionais politicamente muito pouco confiáveis, segundo os cânones do regime (ESCOREL, 1998; PIRES-ALVES \& PAIVA, 2006).

Isto significava também um cenário de oportunidades para jovens profissionais. No campo dos recursos humanos, um emergente grupo de médicos e profissionais de saúde dedicados a este tema logrou mobilizar capacidades da Opas e de áreas sensíveis dos ministérios da Saúde e do Planejamento, para realizar a gênese e a implementação de um programa de cooperação. Em sua quase totalidade, a equipe de condução do PPREPS foi formada por profissionais brasileiros. Mais do que isso, também foram nacionais as fontes de competência mobilizadas para realizar a modelagem do programa, inclusive no tocante a aspectos conceituais e metodológicos. Neste particular, a cooperação suscitou a reunião, atualização e reconfiguração para a aplicação na saúde, de competências acumuladas ao longo de várias iniciativas inovadoras, implementadas inclusive com a ajuda de organismos internacionais, e uma efervescente comunidade engajada na crítica das práticas vigentes ao longo do regime autoritário (ESCOREL, 1998; SANTOS, 2002; FERREIRA, 2005; SANTANA, 2005).

Para fazer frente aos ambiciosos objetivos do PPREPS, a Cooperação Técnica precisou operar a partir de um arranjo institucional peculiar. Era preciso considerar uma natureza centralizadora do regime, combinada, todavia, com a existência das três esferas jurídico-formais de governo (federal-estadualmunicipal) que caracterizam o estado brasileiro, todas diretamente responsáveis por ações nas áreas de educação e ou saúde. Dada a característica multisetorial imprimida ao programa, seria preciso, ainda, mobilizar estruturas e trafegar 
por áreas de competência de pelo menos quatro pastas ministeriais. Assim, os arranjos institucionais adotados para o funcionamento do PPREPS envolveram a constituição de um colegiado multi-institucional para orientação do programa e de um grupo técnico diretivo, designado pela Opas e as pastas ministeriais mais diretamente envolvidas. A este último coube as principais responsabilidades, inclusive de condução política, tendo sido dotado de considerável autonomia, inclusive financeira. Desta forma foi permitido ao programa assumir uma identidade institucional algo ambígua: ora investindo-se de autoridade, na medida em que era parte das estruturas da administração direta e vinculado aos seus centros de decisão; ora assumindo a condição de programa conduzido por uma organização intergovernamental, desvinculada do governo, quando mais conveniente. A Cooperação Técnica optou por adotar a estratégia de promover o fortalecimento de instâncias regionais - sobretudo aquelas com atribuições ou alcance estadual - como forma de ampliar e capilarizar a sua capacidade de atuação. Esta estratégia foi acionada na implementação do PPREPS e em vários momentos da trajetória da cooperação, e ela foi, sem dúvida, informada pelas noções de unicidade, descentralização e hierarquização presentes na concepção de sistema público de saúde, tal como defendida por um emergente movimento de reforma da saúde. Assim, a cooperação ajudou a instituir e fortalecer Núcleos de Saúde Coletiva em várias universidades nos estados da federação; ela igualmente promoveu a criação de órgãos de desenvolvimento e gestão de recursos humanos junto às secretarias estaduais de saúde; ela buscou mobilizar universidades e serviços para a implantação de ações de integração docente-assistencial, organizadas a partir da noção de distrito de saúde; ela procurou instituir, também nos estados, escolas técnicas de saúde, orientadas para a formação em serviço de trabalhadores em nível auxiliar e técnico. Da mesma maneira, quando empreendeu a realização de cursos formativos de gestores de recursos humanos e de gerência das unidades básicas de saúde, procurou fazê-lo de forma descentralizada, a partir das secretarias de estado e de universidades situadas nas mesmas jurisdições loco-regionais.

A implementação desta estratégia, no contexto da sua realização, contribuiu para a urdidura em rede de uma comunidade de especialistas nos temas da gestão do trabalho e da educação na saúde, o que favoreceu uma maior presença relativa desta temática na agenda da reforma da saúde. E este tipo de atuação em rede tendeu a se tornar um estilo de ação e uma espécie de imagem objetivo da cooperação em recursos humanos no tocante aos seus aspectos organizacionais.
As equipes diretivas do PPREPS estiveram intimamente associadas ao moderno movimento da reforma sanitária brasileira. Esta associação envolveu fornecer apoio logístico ao movimento e uma participação ativa como parte de suas lideranças. Esta proximidade se fez sentir, também, - o que é importante assinalar - no tocante aos aspectos conceituais e programáticos. Nos documentos de referência do programa e das suas ações mais importantes foi manifesta a preocupação de concebê-los como parte da agenda da reforma e componente estruturante no processo de implantação do SUS. Considerada esta dimensão programática, afirmavase a utilização do sistema de saúde, em sua dimensão assistencial, como um recurso pedagógico; o estímulo a uma melhor integração multiprofissional, de forma a permitir uma maior integralidade das ações de saúde; a reorganização das instituições docentes e prestadoras de serviços, bem como o desenvolvimento de uma estrutura curricular e técnicopedagógica mais afinada com a idéia de integração entre docência e serviço.

\section{Política externa e agendas de cooperação}

Esta seção se dedica à discussão, em perspectiva história, da política externa brasileira em seus últimos 40 anos. Este recuo histórico se justifica na medida em que ele torna possível o exame dos principais elementos de ruptura e continuidade na forma pela qual o país interagiu com outras nações e organismos internacionais, especialmente quanto aos mecanismos de cooperação internacional sul-sul ou entre países em desenvolvimento.

O modus operandi da política externa brasileira, cujas origens a literatura muitas vezes remonta à figura do chanceler José Maria de Paranhos Junior, o Barão do Rio Branco (1902-1912), se consagrou tanto pela postura pacifista, não-intervencionista, pelo respeito aos códigos e acordos internacionais, como também pela disposição em estabelecer laços de cooperação técnica e humanitária com demais nações (RODRIGUES \& SEITENFUS, 1995).

A despeito desta percepção oficial acerca da política externa brasileira consagrar o país como uma nação aberta ao multilateralismo e à submissão de suas políticas a pressupostos de ordem ética e moral, o exame mais cuidadoso acerca de sua política exterior revela que esta esteve tanto ajustada às vicissitudes do contexto internacional, como também informada pelos dilemas presentes no cenário interno. Deste modo, nem sempre ocorreu um alinhamento automático ou mesmo uma coerência entre agendas domésticas e política exterior. 
Esta aparente contradição diz respeito ao fato das regras, os atores e à natureza do jogo das forças políticas internas não necessariamente corresponderem àquelas que se situam em âmbito internacional. Isto explicaria a possibilidade de convivência entre iniciativas de cunho autoritário no plano interno e perspectivas mais liberais ou "à esquerda" no plano internacional, por parte de um mesmo governo (OLIVEIRA \& LESSA, 2006).

A hegemonia da noção de um projeto nacional de desenvolvimento, por exemplo, que remonta a meados do século XX e que se manteve em vigor durante todo o regime militar, legou à política externa brasileira uma trajetória de busca insistente, sempre renovada, por autonomia internacional. Uma tendência que alcançou maior grau de consolidação doutrinária durante o regime militar (VIZENTINI, 2005, p.39). Sua vigência, contudo, não foi linear e uniforme durante todo o regime. O governo do general Castelo Branco (1964-1969), representou um importante recuo com relação à diplomacia multilateral e hemisférica da Política Externa Independente, a PEl, iniciativa dos governos de Jânio Quadros (1/1961-8/1961) e João Goulart (1961-1964). Com Castelo o país se enquadrava na moldura da Guerra Fria, tornando-se aliado automático dos Estados Unidos da América, de quem esperava, em contrapartida, receber apoio econômico e cooperação internacional. Este alinhamento automático constrangeu por alguns anos a ação diplomática brasileira aos limites impostos pelos interesses norte-americanos na região das Américas, rompendo assim com um padrão de diplomacia mais global, até então orientado pela PEI.

Neste período, embora o país mantivesse relações comerciais e políticas com o bloco soviético, o intercâmbio comercial foi drasticamente reduzido. Em maio de 1964, o país rompia relações diplomáticas com Cuba. No ano seguinte, atendendo pedido da Casa Branca, o Brasil enviaria tropas à República Dominicana, sob a bandeira da OEA, a fim de evitar que a guerra civil neste país gerasse um novo regime socialista. Esta medida não deixou de gerar grande mal-estar diplomático com nossos vizinhos latinoamericanos. Registrou-se igualmente um afastamento dos países africanos e asiáticos e ao Movimento dos Países NãoAlinhados.

Esta política externa obedecia a uma lógica, segundo a qual o país se afastava politicamente de qualquer inspiração ideológica supostamente de esquerda e se via, por outro lado, comprometido em estabelecer bases políticas e institucionais sólidas para o ingresso do capital financeiro internacional. Alusões às reformas sociais, inclusive no campo da política externa, foram abolidas. Apesar disso, certa margem de autonomia da política externa foi preservada. Exemplo disso foi a recusa brasileira à solicitação norteamericana de enviar tropas à guerra do Vietnã.

O Ministério das Relações Exteriores (MRE) continuou concentrando quadros técnicos afinados com a idéia de "projeto nacional". É bem verdade que parte destes quadros, sobretudo aqueles considerados pelo regime como ideologicamente radicais, foram encaminhados para postos de trabalho secundários na estrutura do ministério. No geral, contudo, o MRE se viu relativamente poupado de intervenções mais sistemáticas por parte dos militares, uma vez que estes encaravam o padrão de formação e a hierarquia vigente no ambiente profissional diplomático como semelhantes àquela da caserna. E de fato, pouco a pouco, a política externa do regime foi se tornando semelhante àquela praticada pela $\mathrm{PEI}$ (VIZENTINI, 2005).

Nesse contexto, o governo do general Costa e Silva (1967-1969) é visto como um ponto de ruptura com relação ao governo anterior e de certa retomada dos valores e perspectiva que guiaram a política externa brasileira às vésperas do regime militar. A Diplomacia da Prosperidade do chanceler Magalhães Pinto, com sua ênfase nas idéias de autonomia internacional e desenvolvimento nacional, muito se assemelhava à $\mathrm{PEI}$, ainda que não fizesse nenhuma referência às reformas sociais. O Brasil não mais se definia como nação do Ocidente, mas como país do Terceiro Mundo e propugnava uma aliança com os países em desenvolvimento a fim de reverter uma ordem internacional considerada injusta e hostil. É exemplar deste contexto o fato do representante do Brasil, no contexto da II Conferência das Nações Unidas para o Comércio e Desenvolvimento-UNCTAD ter sido indicado para a presidência do recém criado Grupo dos 77, um movimento dos países do Terceiro Mundo voltado para o desenvolvimento e que, segundo Vizentini (2005), seria uma espécie de variante econômica dos Não-Alinhados.

Para a América Latina, de um distanciamento e frieza nas relações diplomáticas típicos do início do regime militar, o país orientou-se para uma melhor integração regional horizontal. Sem que deixasse de produzir atritos com os Estados Unidos, pouco a pouco o país se afastava da doutrina de um panamericanismo rumo a um latino-americanismo.

Desta forma, o Brasil compartilhava o entendimento internacional, crescente nos anos 1970, de que havia já certo acúmulo de experiências positivas entre os países em desenvolvimento, experiências estas passíveis de serem compartilhadas com outras regiões e/ou nações com características semelhantes. Foi neste contexto que as Naç̃̃es 
Unidas fomentaram a "cooperação técnica entre países em desenvovimento" (CTPD), ou simplesmente cooperação horizontal, em oposição à idéia de assistência técnica ou à noção de cooperação norte-sul.

Já sob a orientação do chanceler Mário Gibson Barboza, durante todo o governo Médici (1969-1974), a política externa brasileira aparou os principais pontos de conflito com os Estados Unidos. O país imediatamente abandonou o discurso de solidariedade terceiro-mundista e seus fóruns de expressão. Esta aparente convergência à política externa norte-americana, contudo, não fez calar os ataques brasileiros - agora feitos em seu próprio nome - à maneira como eram então organizadas as finanças e o comércio internacional. O Brasil manteve a recusa de assinar o Tratado de Não-Proliferação, TNP, e ainda avançou em seu processo de qualificação tecnológica e desenvolvimento de uma indústria armamentista nacional (VIZENTINI, 2005).

O Brasil encontrava, na verdade, uma conjuntura política latino-americana bastante favorável, espaço para se configurar como potência regional. De um lado, o país apresentava uma economia vigorosa; de outro, a instabilidade política no continente, com golpes de estado no Chile, no Uruguai e na Bolívia, produziam um contexto em que o país se apresentava como aliado estratégico fundamental para os norte-americanos.

Foi neste cenário que a chamada diplomacia do interesse nacional, levada a cabo pelo chanceler Gibson Barboza, procurou tirar proveito das brechas existentes no sistema internacional. Por meio de uma diplomacia bilateral, sobretudo com relação aos países considerados em condição econômica e política mais frágil, o Brasil foi exercendo maior influência internacional. América Latina, Central e África foram alvos privilegiados pela diplomacia brasileira neste período e convênios de cooperação nas áreas da cultura, tecnologia e comércio foram assinados. A aproximação com os países árabes se tornou mais expressiva à medida que a crise do petróleo se agravava, ao longo da década de 1970. Estas iniciativas se adensariam durante a gestão do chanceler Azeredo da Silveira (1974-1979), durante o governo do general Geisel.

Nesse contexto o país procurou afirmar sua presença no cenário internacional de forma mais contundente. Para isto exerceu maior protagonismo junto à Organização das Nações Unidas e outros organismos internacionais, agora com especial convergência com o Terceiro Mundo e suas instituições representativas. O Brasil reconheceu o governo socialista do Movimento Popular de Libertação de Angola, MPLA; estreitou relações econômicas e políticas com Moçambique e, de forma geral, incrementou suas relações diplomáticas com o continente africano.
O universalismo do chanceler Saraiva Guerreiro, já sob o comando do general Figueiredo (1979-1985), não seguiu caminho diferente. O cenário internacional apresentavase de forma bastante desfavorável, sobretudo no que diz respeito à crise econômica que se manifestava de modo grave. O país, contudo, mantinha ainda atuação destacada em fóruns internacionais e em convergência com outros países do Terceiro Mundo. Durante a gestão do chanceler Guerreiro, o Brasil solidificaria suas relações diplomáticas com a África e com a América Latina. Os incidentes protagonizados pelos norte-americanos na Nicarágua, em El Salvador e em Granada, no início da década de 1980, levaram o Brasil a integrar o Grupo de Apoio a Contadora, nítido sinal de convergência da diplomacia brasileira com os mexicanos, venezuelanos e argentinos, em uma crítica aberta à política externa intervencionista norte-americana desenvolvida pelo governo Reagan. Segundo Vizentini (1995, p. 65), pela primeira vez na história da política externa do país, a América Latina passava a ser considerada uma prioridade.

Em plena abertura democrática, o ministro das relações exteriores Olavo Setúbal (1985-1986) logo se comprometeu em afastar o país da esfera de influência das nações do chamado Terceiro Mundo e de sua agenda de reivindicações. O Itamaraty resistiu ao encaminhamento proposto pelo ministro e no início de 1986, Abreu Sodré (1986-1990) seria empossado como o novo chanceler brasileiro, dando prosseguimento à agenda de trabalho mais ampla dos governos anteriores.

É neste contexto, por exemplo, que se começou a construir a arquitetura político-institucional que permitiu, no início da década de 1990, a criação do Mercado Comum do Sul, o Mercosul. Um nítido movimento em que a integração econômica e uma melhor cooperação técnica e política com os vizinhos tornaram-se prioridades para o governo brasileiro (HIRST, 1996).

Ainda que amplos setores dentro do Itamaraty tenham resistido às mudanças implementadas pelo chanceler Francisco Resek, já sob o governo do presidente Collor de Mello (1990-1992), nos primeiros anos da década de 1990, houve sensível afastamento do país à diplomacia global e multilateral tradicionalmente praticada pela chancelaria brasileira.

Já o governo Itamar Franco (1992-1994), em oposição à política externa praticada pelo governo Collor, teve como uma das suas prioridades a revalorização da presença do Brasil no plano internacional, sobretudo reafirmando a atuação junto aos fóruns internacionais e a retomada do processo de integração regional. Durante o governo 
Itamar, o Brasil reuniu-se com o Grupo dos 15 (Grupo de Consulta e Cooperação Sul-Sul), na cidade de Dacar, Senegal, para discutir uma articulação da Agenda de Paz com a Agenda para o Desenvolvimento, termo recém retomado pelo governo brasileiro.

O governo Fernando Henrique Cardoso (19952002) pôs desafios adicionais à diplomacia brasileira. Cardoso comprometia-se com o desmanche do estado desenvolvimentista, rumo a uma perspectiva liberalizante e integrada aos interesses do capital e do comércio internacionais. O Itamaraty representava justamente um dos focos de irradiação do discurso mais nacionalista dentro do aparelho de estado brasileiro. Habilmente, pela via da diplomacia presidencial, Cardoso passou a assumir pessoalmente a dimensão política da condução da política externa brasileira, restando ao MRE os assuntos técnicoburocráticos (VIGEVANI et al., 2003; VIZENTINI, 2005).

A partir do contexto da Nova República registrouse, ainda, um reordenamento institucional do aparelho burocrático estatal responsável pela política externa nacional, no sentido de torná-lo gerencialmente mais eficaz. Até 1987 havia um duplo comando nesta área: de um lado, a Divisão de Cooperação Técnica do Itamaraty, e, de outro, a Sub-Secretaria de Cooperação Econômica e Técnica Internacional, a Subin. A extinção destas duas agências e a criação da Agência Brasileira de Cooperação, a $A B C$, permitiu formalmente a unificação das funções administrativa e de política externa em um único órgão.

Parte integrante da Fundação Alexandre Gusmão, Funag, vinculada ao MRE, a $A B C$ teria como responsabilidade a operação de programas de cooperação técnica em todas as áreas de conhecimento, entre Brasil, outros países e organismos internacionais. Já sob a orientação do governo Cardoso, a ABC foi integrada à Secretaria-Geral do MRE, tornando-se órgão da Administração Direta.

O governo do presidente Luiz Inácio Lula da Silva, a partir de 2003, aprofundou algumas iniciativas tomadas no governo anterior, retomando, contudo parte da agenda do desenvolvimento, havendo especial investimento nas relações com o Mercosul e a América Latina em seu conjunto. Uma imagem de liderança, pouco a pouco, começou a ser associada ao Brasil e este iniciaria um processo de atração de países em desenvolvimento com o objetivo de construir um grupo com maior poder de barganha frente às nações desenvolvidas. A iniciativa, em 2003, de cooperação entre Índia, Brasil e África do Sul (IBAS) e o fortalecimento do G-20 como fórum decisório internacional situam-se neste cenário (OLIVEIRA, 2005).
Além disso, à uma velha agenda, pautada pelo debate econômico e comercial, juntava-se, cada vez mais, uma agenda denominada soft, cuja premissa central envolvia a capacidade de fortalecer a posição relativa do país pelo exercício de protagonismo em debates pertinentes ao desenvolvimento social, aos diretos humanos, ao ambiente, entre outros temas.

Envolvia igualmente uma crescente percepção de que as questões de saúde requeriam ações globalmente concentradas e a superação de potenciais conflitos entre necessidades de saúde e interesses comerciais, sobretudo no terreno da propriedade intelectual e do acesso a medicamentos, vacinas e tecnologias de diagnóstico, entre outras pautas.

Esse conjunto de elementos fez emergir um novo domínio de ações, então batizado com o termo de diplomacia da saúde, citado em publicações recentes da literatura internacional - Health diplomacy. Sua peculiaridade reside, grosso modo, numa ação sistemática das autoridades públicas, mediante a adoção de políticas programáticas, pelas quais se desenvolveriam mais plenamente possibilidades diversas, inclusive no terreno político e econômico, a partir do exercício da diplomacia no campo da saúde.

A trajetória da política externa brasileira nos seus últimos 40 anos, assim, revela, a despeito de suas rupturas institucionais, importantes elementos de continuidade que representam ativos relevantes num sistema internacional permeado pelas descontinuidades e por forte déficit de governabilidade. A ação mais sistemática do país no manejo de um soft-power de credibilidade, observados nas duas últimas décadas, posiciona o Brasil como ator relevante na arena dos debates globais (LAFER, 2000).

São exemplos destas iniciativas sistemáticas aquelas que atualmente, envolvem a cooperação prestada pelo Ministério da Saúde nas áreas de prevenção e tratamento da malária, HIV/aids; produção de fármacos e imunobiológicos; apoio à descentralização dos serviços de saúde, a partir do modelo adotado pelo SUS no Brasil; desenvolvimento de recursos humanos para a saúde, junto aos países de língua portuguesa, entre outras iniciativas. Estas ações que envolvem cooperação técnica, sobretudo horizontal, alçam as políticas de saúde do país ao status de verdadeiros recursos da política externa, radicalizando, de certa forma, o papel dos assuntos "sociais" na agenda de trabalho da diplomacia. 


\section{Possibilidades de diálogo com as agendas contemporâneas}

A Cooperação Técnica Opas-Brasil, tal como implementada a partir de meados da década de 1970, diante de um contexto institucional singular e em parte favorável, foi capaz de operar como instância catalizadora de um movimento de reforma das instituições de saúde e que se expressava também no domínio das relações entre educação e trabalho em saúde. Em articulação com organizações estatais e extraestatais foi também instância promotora de iniciativas que se revelaram estruturantes deste campo. A complexidade do seu arranjo e inscrição institucional possibilitou um tráfego relativamente autônomo entre posições de governo e de mobilização crítica da sociedade. Ao longo da década de 1990 e nos primeiros anos deste século, esta trajetória - que se institui como tradição - permitiria à Cooperação Técnica, em associação com a peculiaridade da Reforma Sanitária Brasileira, manter uma agenda relativamente crítica àquelas reformas preconizadas pelo Banco Mundial e o ideário neoliberal. Estes conteúdos críticos não se manifestaram livres de conflitos, seja na dimensão interna à Cooperação, seja nas relações com a Oficina Sanitária, em Washington, seja com instâncias de governo e da cooperação internacional. Seja como for, revelam a complexidade das formas possíveis dos empreendimentos de cooperação e de atuação das agências internacionais consideradas ora como atores, ora como espaços de negociação. Nos dias de hoje, os âmbitos de atuação e os cenários institucionais de cooperação técnica entre a Opas e o governo do Brasil ampliaram-se sensivelmente, refletindo a especificidade dos temas de saúde na nova agenda da política externa e da diplomacia (OPAS-BRASIL, 2008). No que concerne à sua política externa, o estado brasileiro tem intensificado sua atenção - também no tocante à saúde - para a cooperação Sul-Sul, em especial àquela orientada ao países de língua portuguesa e da América Latina. A Opas-OMS tem acordado com o país a responsabilidade de atuar como instância estratégica de mediação e catalisadora das possibilidades de cooperação, assim como instância de acompanhamento das iniciativas. Esta agenda contemporânea envolve mobilizar redes colaborativas nacionais e promover a sua articulação com redes regionais na América Latina e África; articular capacidades docentes para a oferta de cursos nas áreas de gestão de políticas de recursos humanos, de saúde global e diplomacia em saúde, de direito sanitário, e de desenvolvimento e políticas públicas, para clientelas nacionais e dos países dos blocos prioritários da cooperação externa em saúde do Brasil; assim como desenvolver projetos de cooperação horizontal em áreas de interesse comum entre os países: educação de técnicos em saúde, saúde materno-infantil, controle de doenças, entre outros ítens programáticos (OPAS-BRASIL, 2008). Envolve, ainda, capacitar organizações brasileiras para a cooperação e promover enlaces com as capacidades instaladas nos países. Esta nova circunstância possibilita também, à Representação da Opas no Brasil e à Cooperação Técnica em Recursos Humanos, o desafio de re-experimentar, e reinventar, os arranjos institucionais e os modos de operação até agora utilizados. Significa a possibilidade de reproduzir sua própria complexidade, simultaneamente como tradição, como recurso adaptativo e aptidão para uma cooperação entre países renovada.

\section{Referências bibliográficas}

CADRHU, 1991. Curso de Aperfeiçoamento e Desenvolvimento de Recursos Humanos de Saúde Brasília: Opas, 1991 (Série Desenvolvimento de Recursos Humanos, 3).

CASTRO, J. L. Protagonismo silencioso: a presença da Opas na formação de Recursos Humanos em Saúde no Brasil. Natal: Observatório RH-NESC UFRN/ MS/Opas/ OMS, 2008. $267 p$.

CUETO, M. O Valor da Saúde: história da Organização PanAmericana da Saúde. Rio de Janeiro: Editora Fiocruz, 2007.

ESCOBAR, A. La intervención del Tercer Mundo: construción e desconstrución del desarollo. Santa Fé de Bogotá: Grupo Editorial Norma, 1998.

ESCOREL, S. Reviravolta na Saúde: origem e articulação do movimento sanitário. Rio de Janeiro: Ed. Fiocruz, 1998.

FERREIRA, J. R. Estrategias internacionales em educación médica: asistencia técnica y cooperation técnica. Educación Médica y Salud, v. 10, n. 4, p. 335-44, 1976.

FERREIRA, J. R. Depoimento a Carlos H. A. Paiva, Fernando Pires-Alves, Gilberto Hochman e Janete Castro. (Rio de Janeiro, 15-16 de marca de 2005). Transcrito por Annabella Blyth. Conferência por fidelidade por Alex dos Santos da Silveira. 4 horas.

FINNEMORE, M. National Interests in International Society. Ithaca: Cornell University Press, 1996.

HIRST, M. "La dimension política Del mercosur: actores, politización y ideologia". Estudos Avançados, v.10, n.27, p. 217-50,1996. 
LAFER, C. "Brasil: dilemas e desafios da política externa". Estudos Avançados, v. 14, n.38, p. 260-7, 2000.

OLIVEIRA, H. A; LESSA, A. C. L. Política internacional contemporânea. Mundo em transformação. São Paulo: Saraiva, 2006.

OLIVEIRA, M. "Alianças e coalizões internacionais do governo Lula: o IBAS e o G-20. Rev. Bras. Política Internacional. Brasília. Julho-dezembro, v.48, n.2, 2005

OPAS-Organização Pan-Americana de Saúde/Brasil. Acordo para um Programa Geral de Desenvolvimento de Recursos Humanos para a Saúde no Brasil. Brasília: 14 dez. 1973.

OPAS-Organização Pan-Americana de Saúde/Brasil. Acordo Complementar ao Acordo para um Programa Geral de Desenvolvimento de Recursos Humanos para a Saúde no Brasil. Brasília, 8 ago. 1975.

OPAS-Organização Pan-Americana de Saúde/Brasil. Unidade Técnica de Políticas de Recursos Humanos. Relatório de Gestão: Período - $2^{\circ}$ semestre de 2008. [Termo de Cooperação N 41 - $1^{\circ}$ TA - Programa de Cooperação Internacional em Saúde. Brasília, 2008]

PIRES-ALVES, F. A.; PAIVA, C. H. A. Recursos Críticos. História da cooperação técnica Opas-Brasil em Recursos Humanos para a Saúde (1975-1988). Rio de Janeiro: Ed. Fiocruz, 2006.

PDRHS-Programa de Desenvolvimento de Recursos Humanos para a Saúde. Programa de Desenvolvimento de Recursos Humanos para a Saúde - Opas/Brasil. Mimeo, [Brasília], jan. 1985.

PPREPS-Programa de Preparação Estratégica de Pessoal de Saúde. Programa de Preparação Estratégica de Pessoal de Saúde - Opas/Brasil. Mimeo, Brasília: MS/MEC/Opas, jun. 1976, p. 12-16.

PPREPS. Programa de Preparação Estratégica de Pessoal de Saúde - Opas/Brasil. Relatório anual de 1978. Brasília: MS/MEC/Opas, março de 1979.
RODRIGUES, J. H.; SEITENFUS, R. A. S. Uma história diplomática do Brasil (1531-1945). Rio de Janeiro: Civilização Brasileira, 2005.

RIST, G. The History of Development: from Western Origins to Global Faith. Nova Deli: Academic Foudation, 2002.

ROCHA, J. S. Y. A integração docente assistencial na educação médica no Brasil. Rev. Bras. Educação Médica, v. 9, n. 3, p.198-206, 1985.

\section{SANTANA, J. F. P. Conferência de Fidelidade por Alex} dos Santos da Silveira. Depoimento a Carlos H. A. Paiva, Fernando Pires-Alves, Gilberto Hochman e Janete Castro. (Rio de Janeiro, 21-22 de fevereiro de 2005). Transcrito por Andréa Ribeiro. 5 horas.

SANTANA, J. F. P. Conferência de Fidelidade por Alex dos Santos da Silveira. Depoimento a Carlos H. A. Paiva e Fernando Pires-Alves [Entrevista II], (Brasília, de outubro de 2006). Transcrito por Andréa Ribeiro. 5 horas.

SANTOS, I. dos. Izabel dos Santos, a arte e a paixão de aprender fazendo. (Depoimento para Janete Lima de Castro, José Paranaguá de Santana e Roberto Passos Nogueira). Editora Observatóriorh/NESC/UFRN, 2002.

SESU-MEC - Secretaria de Ensino Superior. Relatório do Grupo Interministerial de Recursos Humanos para a Saúde. Brasilia: MEC-SESU, 1981 (Série Cadernos de Ciências da Saúde, $\left.n^{\circ} 4\right)$, 1981, p. 5-11.

TAFFET, J. F. Foreign Aid as Foreign Policy: the alliance for progress in Latin America. New York: Routledge, 2007.

VIGEVANI, T; OLIVEIRA, M.; CINTRA, R. Política externa no período FHC: a busca de autonomia pela integração. Tempo Social. São Paulo: USP, novembro de 2003.

VIZENTINI, P. F. Relações internacionais do Brasil. De Vargas a Lula. São Paulo: Ed. Fundação Perseu Abramo, 2005. 